Objectives: Our purposes were to describe and compare the incidence of OI in RA treated by non-TNF-targeted biologics.

Methods: We performed a retrospective longitudinal observational study from 2007 to 2017. We included subjects followed in our outpatient clinic, diagnosed with RA according to ACR criteria, whom started treatment with a bDMARD [rituximab (RTX), abatacept (ABA), or tocilizumab (TCZ)]. According to the microbiologist criteria, we consider OI when there was a positive culture (for Virus, Fungus, bacterial or parasitary) or compatible symptoms that responded to specific treatment. Severe IO was considered if required hospitalisation. We also collected secondary variables: sociodemographic, clinical and other treatments. We used survival techniques to estimate the incidence of Ol, expressed per 1000 patientyear [Cl 95\%]. Exposure time was defined from the start date of each bDMARDs until the development of an Ol, discontinuation, loss of follow up or end of study (01/02/2017)

Results: We analysed a total of 164 patients with 219 different courses of bDMARDs treatment. Of these, $76 \%$ were women with a mean age at first bDMARD of $61.4 \pm 15$ years. Rheumatoid factor was positive in $73.6 \%$. Main comorbidities were: Hypercholesterolemia (53.3\%), Hypertension (53.2\%), Depression (25\%), Diabetes (15\%), and Ischaemic Heart Disease (9.8\%). VSG mean was $38 \pm 28$, and the mean WBC count was $7.8 \pm 2.7$. The median time from onset of RA until onset of bDMARD was 2.8 years [0.8-6.2]. Of these, 132 were on RTX, 47 were on ABA and 40 were on TCZ. There were 12 OI ( 9 with RTX, 2 with ABA and 1 with TCZ). RTX have 2 Fungus (Candida krusei and Klebsiella), and 7 Virus (4 Herpes Zoster, 1 virus $B$ reactivation, 1 virus $C$ reactivation). OI for ABA was 2 Virus (1 Herpes Zoster, 1 virus $B$ reactivation), while we found one virus OI with TCZ Fungus (Herpes Zoster). There were no bacterial or parasitary OI. Global incidence rate of OI was 30.49 [17.3-53.6]. The incidence of Ol was 38.92 [20.2-74.8] for RTX, followed by ABA with 21.61 [5.4-86.4], and TZC with 14.3 [2-101.6]. We found 3 severe $\mathrm{Ol}$ (2 fungus infections, 1 virus $B$ reactivation). The incidence of severe OI was 7.62 [2.4-23.6], all of them requiring hospitalisation with no deaths. Severe OI have a higher incidence for men 21.1 [5.2-84.2] than women 3.3 [0.4-23.7]. All patients with severe Ol were taking corticosteroids, and at least one synthetic DMARD. TCZ did not have any severe OI, and the incidence of severe OI was 10.8 [1.5-76.7] for ABA, followed by RTX with 8.6 [2.134.5].

Conclusions: The incidence of $\mathrm{Ol}$ in three non-TNF-targeted biologics in real life conditions is described. Incidence found was near 31 cases per 1000 patients year. Virus and fungus are the OI more frequents in these bDMARDs. Doctors using bDMARDs should be concerned about this problem and be aware for the detection and management of OI.

Disclosure of Interest: None declared

DOI: 10.1136/annrheumdis-2018-eular.4534

\section{AB0452 BIOLOGICAL THERAPY ADVERSE EVENTS IN BIOBADAGUAY REGISTRY}

M. Franco ${ }^{1}$, Z. Morel ${ }^{1}$, M.G. Avila-Pedretti ${ }^{1}$, S. Cabrera-Villalba ${ }^{1}$, I. Acosta Colman $^{2}$, P. Babak ${ }^{1}$, P. Melgarejo ${ }^{1}$, G. Elizaur ${ }^{1}$, P. Delgadillo' ${ }^{1}$, D. Cordovilla Montero $^{3}$, J. Losanto ${ }^{2}$, G. Babak ${ }^{1}$, L. Román ${ }^{2}$, E. Paredes ${ }^{1}$, J. Mazzoleni $^{1}$, P. de Abreu ${ }^{4}$, on behalf of BIOBADAGUAY. ${ }^{1}$ Rheumatology, Hospital Central del Instituto de Previsión Social; ${ }^{2}$ Rheumatology, Hospital de Clínicas, Asunción, Paraguay, ${ }^{3}$ Rheumatology, Insituto Nacional de Reumatología, Montevideo, Uruguay; ${ }^{4}$ Rheumatology, Sociedad Paraguaya de Reumatología, Asunción, Paraguay

Background: BIOBADAGUAY is the Paraguayan/Uruguayan registry of adverse events $(A E)$ in patients with inflammatory rheumatic conditions under biologic therapy (BT)

Objectives: To determine the frequency and severity of $A E$ in patients under $B T$ from the BIOBADAGUAY registry

Methods: Prospective, observational study of undetermined length to verify the efficacy, safety and survival of the BT. The methodology applied is available at https//biobadaguay.ser.es. For the present study epidemiological and clinical variables, BT, type and severity of $A E$ were analysed. The incidence rate (IR) was calculated as the total number of adverse events per 1000 patients/year and the incidence rate ratio (IRR) was analysed using the Poisson regression model.

Results: 778 BT were analysed (56.6\% adalimumab, $23.7 \%$ etanercept, $9.6 \%$ tocilizumab, 5.7\% rituximab, 3.5\%infliximabm, 0.5\%golimumab, $0.38 \%$ infliximab biosimilar, $0.13 \%$ abatacept). In these, $330 \mathrm{AE}$ were observed, $256(77.6 \%)$ mild and $74(24.4 \%)$ severe. The global IR of AE was $143.9(95 \% \mathrm{Cl}, 128.8-160.8)$ and 32.6 (95\% Cl,25.3-40.5), 111.6 (95\% Cl, 98.4-126.2) for severe and mild respectively. Infection was the most frequent AE in $175(53.0 \%)$ and $39(22.3 \%)$ of them were severe. Infection's IR was 76.3 (95\% Cl,65.4-88.5), $59.3(95 \% \mathrm{Cl}, 49.76-$ $70.2)$ and $17.0(95 \% \mathrm{Cl}, 12.1-23.3)$ for global, severe and mild respectively. Out of the 39 severe $A E$, respiratory infections were the most frequent in $43.6 \%$ of the cases. 5 tuberculosis, 6 malignancies and 6 deaths were observed.
When analysing the IR according to diagnosis, Idiopathic Juvenile Arthritis (JIA) was associated with a higher IR of global AE when comparing to the other diagnosis $(\mathrm{IRR}=2.3[95 \% \mathrm{Cl}, 1.6-3.4] \mathrm{p}=4.27 \times 10-6)$. RA diagnosis was significantly associated with a higher risk of severe $A E(I R R=2.20[95 \% \mathrm{Cl}, 1.2-4.1]$ $\mathrm{p}=1.17 \times 10-2)$. tocilizumab was significantly associated with a higher incidence of global $\mathrm{AE},(\mathrm{IRR}=2.69[95 \% \mathrm{Cl}, 1.90-3.82] \mathrm{p}=3.13 \times 10-8)$ and severe ones $(\mathrm{IRR}=3.34[95 \% \mathrm{Cl}, 1.81-6.1] \mathrm{p}=1.10 \times 10-4)$. Adalimumab was significantly associated with a lower rate of global $\mathrm{AE}(\mathrm{IRR}=0.6[95 \% \mathrm{CI}, 0.4-0.8]$ $p=1.86 \times 10-4)$.

Abstract AB0452 - Table 1. Incidence rate and incidence rate ratio of adverse events according to diagnosis and biological therapy

\begin{tabular}{lccc}
\hline Variable & \multicolumn{1}{c}{ IR } & IRR & P value \\
\hline Psoriasic Arthritis & $88[52,2-139,1]$ & $0,59[0,33-1,04]$ & $7,03 \mathrm{e}-02$ \\
Ankylosis Spondylitis & $102,3[68,0-147,8]$ & $0,68[0,40-1,17]$ & $1,63 \mathrm{e}-01$ \\
Rheumatoid Arthritis & $134,2[115,6-155,0]$ & $0,85[0,62-1,15]$ & $2,81 \mathrm{e}-01$ \\
Idiopatic Juvenile Arhritis & $286,4[229,4-353,2]$ & $2,34[1,63-3,37]$ & $4,27 \mathrm{e}-06$ \\
Adalimumab & $113,5[96,9-132,1]$ & $0,57[0,43-0,77]$ & $1,86 \mathrm{e}-04$ \\
Etanercept & $190,4[152,7-234,6]$ & $1,44[1,03-2,02]$ & $3,30 \mathrm{e}-02$ \\
Rituximab & $66,9[26,9-137,8]$ & $0,45[0,18-1,13]$ & $8,93 \mathrm{e}-02$ \\
Infliximab & $75,0[24,3-175,0]$ & $0,51[0,21-1,23]$ & $1,35 \mathrm{e}-01$ \\
Tocilizumab & $340,0[261,8-434,2]$ & $2,69[1,90-3,82]$ & $3,13 \mathrm{e}-08$ \\
\hline
\end{tabular}

IR: incidence, IRR: incidence ratio (per 1000 patients year)

Conclusions: $A E$ were mild in general and infections were the most frequent. In the present study, it was found that JIA and treatment with tocilizumab presented a higher IRR of AE while RA presented a higher rate of severe $A E$.

Disclosure of Interest: None declared

DOI: 10.1136/annrheumdis-2018-eular.6725

\section{AB0453 BIOLOGICAL THERAPIES RETENTION RATE IN TWO SUDAMERICAN COUNTRIES. DATA FROM BIOBADAGUAY REGISTRY}

M.G. Avila-Pedretti ${ }^{1}$, P. Melgarejo ${ }^{1}$, M. Franco ${ }^{1}$, Z. Morel $^{1}$, J.G. Elizaur ${ }^{1}$,

P. Delgadillo ${ }^{1}$, I. Acosta-Colman ${ }^{2}$, S. Cabrera ${ }^{1}$, D. Cordovilla Montero ${ }^{3}$,

J. Losanto ${ }^{2}$, L. Román ${ }^{2}$, E. Paredes ${ }^{1}$, J. Mazzoleni ${ }^{1}$, P. deAbreu ${ }^{4}$, on behalf of BIOBADAGUAY. ${ }^{1}$ Rheumatology, Hospital Central del Instituto de Previsión

Social; ${ }^{2}$ Rheumatology, Hospital de Clínicas, Asunción, Paraguay; ${ }^{3}$ Rheumatology, Instituto Nacional de Reumatología, Montevideo, Uruguay, ${ }^{4}$ Rheumatology,

Sociedad Paraguaya de Reumatología, Asunción, Paraguay

Background: The retention rates (RR) of biological therapies (BT) have been extensively studied in European countries and the United States, but there is a lack of information about them in emerging populations.

Objectives: To analyse BT retention rates and variables associated to them at the BIOBADAGUAY registry

Methods: Patients with a chronic inflammatory arthritis enrolled in the Paraguayan-Uruguayan biological register (BIOBADAGUAY) between2015 and 2017 where included in the study. Phase I of the study was focused in the global RR analysis and association with clinical and epidemiological variables. In phase II we analysed BT retention rate according to different discontinuation motives and association with clinical and epidemiological variables. Survival analysis was performed using Kaplan-Meier estimators and proportional hazard regression models

Results: A total of 778 BTs where included in the study (etanercept $n=184$, adalimumab $n=440$, rituximab $n=44$, infliximab $n=27$, tocilizumab $n=75$, and others $\mathrm{n}=8$ ). The underlying diagnosis associated to these BTs were rheumatoid arthritis (RA;58.2\%), juvenile arthritis (JIA; $14.2 \%$ ), ankylosing spondylitis (SA; 12.5\%) and psoriatic arthritis (PA; $8,0 \%$ ).

In phase I we found that mean survival times were $322( \pm 17.9), 315( \pm 22.32), 289$ $( \pm 8.52)$ and $233( \pm 16.69)$ weeks for AS, PA, RA and JIA respectively. The surviva association analysis has shown that JIA diagnosis $(p=2.26 \times 10-4, H R=1.80$ [95\% $\%$ Cl, 1.32-2.46]), corticosteroids ( $\mathrm{p}=1.54 \times 10-2, \mathrm{HR}=1.38[95 \% \mathrm{Cl}, 1.06-$ 1.79]), and previous $\mathrm{BT}(\mathrm{p}=3.32 \times 10-2, \mathrm{HR}=1.43[95 \% \mathrm{Cl}, 1.03-1.98])$ were variables significantly associated with a lower $\mathrm{BT}$ retention.

In phase II, we stratified the survival analysis by cause of discontinuation. We found that corticoids $(p=9.48 \times 10-4 \mathrm{HR}=2.02[95 \% \mathrm{Cl}, 1.33-3.06])$, female gen der $(\mathrm{p}=4.36 \times 10-2, \mathrm{HR}=1.66[95 \% \mathrm{Cl}, 1.01-2.72])$ and previous $\mathrm{BT}(\mathrm{p}=2.56 \times$ $10-2, \mathrm{HR}=1.72$ [95\% Cl, 1.07-2.78]) were associated with lower BT retention due to inefficacy. When we analysed withdrawn according to adverse events, we found that RA $(\mathrm{p}=02,80 \times 10-2, \mathrm{HR}=1,83[\mathrm{IC} 95 \% 1,07-3,15])$, previous BT $(p=4,83 \times 10-2, H R=1,76[$ IC 95\% 1,00-3,09]) and age $(p=7,14 \times 10-5, H R=1,05$ [IC 95\% 1,02-1,05]) were significantly associated with therapy discontinuation. In the group of treatments with discontinuation due to remission, we found that JIA diagnosis $(p=7,93 \times 10-8, H R=30,58$ [IC 95\% 8,77-106,71]), age $(p=7,83 \times 10-6$ 